\title{
CONSEQUENCES OF LOSS OF COMMON PROPERTY RESOURCES IN THE SELECTED BLOCK, DINDIGUL DISTRICT OF TAMILNADU
}

\author{
Dr. P. Murugesan \\ Assistant Professor, Centre for Rural Development, Annamalai University, \\ Annamalai Nagar
}

\begin{abstract}
Common property land resources include grazing ground, community pasture, village forests and woodlots, and village sites, on which the villagers have legal usufructuary rights; these land resources also include all another land formally held by the panchayat or a community of the villages (NSS $54^{\text {th }}$ round). For a collection of data of common land resources de jure and e facto approaches were considered. Forest land resources which are under the jurisdiction of the forest department was also considered as poor dependent rural communities are directly or indirectly dependent on the forest for livelihoods. From the report of NSS $54^{\text {th }}$ round, it is observed that $15 \%$ of India's total geographical area substantially forms a part of common land resources. Consequences of loss of common property resources and depletion of common property resources resulted largely because there was no private cost for using these resources. Privatization of common property resources in the arid zone has invariably meant the conversion of common property resources land into cropland.
\end{abstract}

KEYWORDS: Consequences, natural resources, directly, indirectly, CPR, forests, harvesting, forest resource, grazing land, ground .etc.

\section{INTRODUCTION}

Common Property Resources are commonly owned by a recognized group of masses which is usually regulated by social norms and legally enforceable regulations. It comprises of all those resources that included the village pastures and grazing lands, forests and woods, secured and unclassified government forests, wastelands, common threshing lands, water shed, ponds, tanks, rivers, streams, water reservoirs, canals and irrigation canals which are for the purpose of community use of the villagers. In pre-British India, a vast part of the nation's natural resources was easily accessible by the rural masses and under the control of the local communities. Village commons grazing land and water resources constitute an indispensable part of the livelihood basis of rural communities; they are the primary source of fodder and water for grazing animals. The poor rural sections of the rural society rely on the common pastures disproportionately, and they take out a big share of their income and dependency from livestock rearing specially sustenance of the goat lot in the villages. For the marginal agricultural advocators and landless laborers, goats and sheep are valuable assets for obvious 
reasons. First and foremost, these call for a low initial investment and also provide consistent income through the sale of milk, meat and other allied products alongside also ensuring the families' nutritional balance. Second, these small ruminants are part of an important role in handling the expenditures of the poor rural households as they are flexible saleable products with low transaction costs (World Bank 2001), which is mandatory for the rural families that periodically migrate to the cities as seasonal labour.

The custodianship of the remaining common property resources was transferred to the village community, represented by village Panchayats (elected councils). The provision of common access continued as in the past, but the old system of management of common property resources disappeared. The charges were in the form of fixed grazing tax per head of the animal, auctioning of produce, levies on users, penalties for violations and so forth. It must be noted, however, that the by-product of such an exploitative mechanism was a management system that protected, maintained, and regulated use of common property resources. The traditional occupational structure in the society ensured that there was less pressure on the croplands even though there was an increase in population. The occupations such as Arts and crafts, exclusive engagement in livestock raising, petty trading, and so on ensured maintenance of a large portion of villagers away from the croplands. The village panchayat did not impose grazing taxes and levies on users, despite being legally empowered to do so. The maintenance and upkeep of common property resources suffered as the Panchayats depended more and more on assistance from the government for this purpose.

Despite a rapid decline in their area and productivity, common property resources constitute an important component of community assets in the dry areas of India and are one of the community's responses to the scarcities and stresses created by agro-climatic conditions. They are sources of a range of physical products, offer employment and income generation opportunities and provide broader social and ecological benefits. The immediate consequence of increased pressure on such resources is their overexploitation and degradation. Their physical degradation is strongly felt and observed, but its quantification is difficult owing to a lack of benchmark data. Nevertheless, case histories and close monitoring do provide basic details. Declines in the number of products available and their yields are the main indicators of physical depletion. For instance, the number of different common property products collected by villagers ranged from 27 to $46 \%$ before 1952 . The decline in the number of products also suggests reduced biodiversity in common property resources.

\section{REVIEW OF LITERATURE}

Pathania M.S, et.al (2019) Since Garrett Harding's study (Hardin 1968), research has been very interested in RCP. The concept was used to explain the adverse effects on the economy, ecology, and the environment. These effects could be more noticeable in the fragile ecosystem of a mountainous region where the degradation of the CPR's land would cause socio-economic disturbances not only in the hills but also in the plains. With increasing human and animal pressure, the size and quality of RCP decrease. Jodha (1986) reported a decrease of 41 to $55 \%$ of the area of village communes over a period of 30 years. The 
downward trend was also noted by Vashist in Himachal Pradesh (1999). The factors responsible for this are agrarian reforms, development programmes, illegal encroachments and the Commercialization of Agriculture (Jodha 1985, Iyengar 1988).

Beck, Tony (2017) observed the causes and process of degradation of CPRS and said that the causes of CPRs fall are human factors such as socio-economic, legal, political, and technical along with environmental factors (physical factors). The causes and procedure of the bending CPR structure in the study area are thus summarized. The main reasons for the decline of CPR, are summarized as 1. Increased stress on CPRs (due to population rise, poverty, and CPR marketing etc). 2. Lack of participatory and inclusive leadership, tradition majorly and often ignores to protect the CPRs without replacing it with best ways, lack of sense of ownership, the indifference of non-monetary CPR values and the impact of Structural changes, etc. 3. Contraction of CPRs (due to unauthorized access to the local leader or other, distribution of CPRs for the purpose of the well-being \& welfare, sale or privatization of CPRS by the Government of the local community and the side effect. 4. Natural calamities, loss of ecological or other such environmental imbalance. Instability and the new mountains pave way for high natural eroding of resources. This can be summarized into two heads - Decline in CPR quality and Decline of the CPRS quantity on account of human and non-human factors.

Curtis R. Martins (2017) examine that a big challenge for Swaziland is how to maximize the use of forests while still maintaining their durability. Forests are depleted and degraded due to poor access control, disparities in the country's term of office and user rights. The research was conducted using the Institutional Analysis and Development (IAD) framework as the underlying scheme. Although access to community forests was limited, the natural sources of forests were open to all. Institutional and Community rules used to regulate access to forests are not effective. There are therefore problems with deforestation, degradation, illegal felling and the lack of involvement of community members to manage forests. The study recommends that local people should be trained for rules regulating access to forests and common rules to be defined at the local level.

Murugesan and Namasivayam (2016) studied the common property resources and their role in the eradication of poverty in rural areas of India. This study confirms that the poverty level has fallen from the head-count relationship to the poverty gap and the poverty gap compared to the Sen poverty index for all categories of entrepreneurs and closet groups. According to the Sen-index of poverty, poverty levels were around 18 to $24 \%$ among land workers, marginal farmers, and smallholders, and from 17 to $37 \%$ of the plan, most remote and delayed reduction groups; are particularly reduced due to the RPC's income. It is surprising that the percentage of poor people fell from $4 \%$ to $0 \%$ for medium-sized farmers by incorporating CPR's income into medium-sized farmers. The share of the poor is dérisaire and has come down from the $4 \%$ to $0 \%$ through the CPR income inclusion by the medium farmers. The ratio of poor is insignificant in the medium farmer's group and is absent in the case of the large farmer's group as per the study and therefore a detailed account in this 
regard is not noted in this section as they fall under the highest part of the occupational ladder status in the rural area.

Mengistu Dessalegn (2016) said that managing shared real estate resources to improve housing must prove sustainable if a systematic management mechanism is established with the establishment of core values for the role of the group. Each group can function better if enough attention is paid to the emerging needs of group members. The Pandiapli has shown that organized efforts, with a well-designed mechanism, can meet the needs of the community in relation to the existence of poor people. Community institutions must also play a crucial role in strengthening the nutrition of the poor. The case is the best instance for the ideal management of CPR for the improvisation of poor livelihoods which been clearly established through this case study.

Chopra and Gulati (2013) Study on the economic benefits of small reservoirs brought the main impact that small reservoirs currently have in rural livelihood generating revenue. Small reservoirs provide a year-round supply of water, allowing small farmers to irrigate their crops in both the wet and dry season. This supports a critical livelihood strategy - that of market-oriented crop production - and delivers a tangible result, generating revenue. As mentioned above, six out of nine households (67\%) interviewed in communities with small reservoirs producing crops using irrigation. Five of these six $(83 \%)$ farmers who use watering water from a small reservoir to produce their vegetables. Specifically, 2 out of 3 households in Buriti Vermelho are practicing watering using a small reservoir. One of the two farmers in Lamarao used water from the small reservoir, and the two respondents who used irrigation in Nucleo Rural Jardim also use a small reservoir. The outcome indicates the importance, role and also the significant role small reservoirs play in the above-mentioned process.

Ostrom (1990) has questioned Garrett Hardin's recommendation on the management of CPRs by privatization or by centralized control by the state. Through case studies and theoretical reasoning, Ostrom (1990) showed that neither privatization nor centralization would necessarily achieve allocative efficiency. A participatory model can be applied to the rational use of common property resources. Especially in a land-based economy like the North East, people's participation in management is absolutely necessary. But this requires strengthening the participatory institutions like Panchayati Raj Institution, CBO, NGOs, and Co-operative societies etc. to mobilize local community resource in economic development. Finally, dependence on CPR especially in rural areas is one unavoidable truth and proper management of the usage of CPR is absolutely necessary so that economic development can go hand in hand with an environment which is the essence of sustainability.

\section{RESEARCH METHODOLOGY}

\section{Objectives}

To study the Socioeconomic characteristics of the respondents in the study area.

To analyze the consequences of loss of common property resources 


\section{Hypotheses}

- Consequences of loss of Common Property Resources for sustainable rural livelihoods.

\section{Sample Design}

The Dindigul District in Tamilnadu consists of 14 blocks. This study was carried out in 5 blocks namely Oddanchatram, Reddiyarchatram, Dindigul, Sanarapatti and Vadamadurai. These blocks were identified based on the high level of CPRs present. From each of the above-identified block, 5 village Panchayats have been selected. Further, 12 households from each village panchayat and a total number of samples selected for the present study it was 300 as detailed below, by using Disproportionate Stratified Random Sampling method.

\section{Data Analysis}

The survey data, after evaluation and coding, have been entered into spreadsheets of Statistical Package of Social Science (SPSS). To understand the nature of the data, frequency tables were prepared, and subsequently, the analysis and tabulation have been carried out using research techniques based on the requirement. Further Percentage Analysis has been performed on the data.

\section{RESULTS AND DISCUSSION}

TABLE 4.1 CONSEQUENCES OF LOSS OF CPRS AND PERCENTAGE DISTRIBUTION OF SAMPLE RESPONDENTS

\begin{tabular}{|c|c|c|c|c|c|c|}
\hline \multirow{2}{*}{\begin{tabular}{|l} 
Background \\
characteristics
\end{tabular}} & \multicolumn{5}{|c|}{$\begin{array}{c}\text { 1-Oddanchatram, 2-Reddiyarchatram, 3-Dindigul, 4- } \\
\text { Sanarapatti, 5-Vadamadurai }(\%)\end{array}$} & \multirow[t]{2}{*}{$\begin{array}{l}\text { Total } \\
(\%)\end{array}$} \\
\hline & 1 & 2 & 3 & 4 & 5 & \\
\hline \multicolumn{7}{|c|}{ 4.1.1 Possible effects of loss of CPR } \\
\hline Unemployment & $\begin{array}{c}28 \\
(26.4)\end{array}$ & $\begin{array}{c}19 \\
(17.9)\end{array}$ & $\begin{array}{c}19 \\
(17.9)\end{array}$ & $\begin{array}{c}20 \\
(18.9)\end{array}$ & $\begin{array}{c}20 \\
(18.9)\end{array}$ & $\begin{array}{c}106 \\
(35.33)\end{array}$ \\
\hline $\begin{array}{l}\text { Affect } \\
\text { livelihoods }\end{array}$ & $\begin{array}{c}26 \\
(16.6)\end{array}$ & $\begin{array}{c}40 \\
(25.5)\end{array}$ & $\begin{array}{c}32 \\
(20.4)\end{array}$ & $\begin{array}{c}34 \\
(21.7)\end{array}$ & $\begin{array}{c}25 \\
(15.9)\end{array}$ & $\begin{array}{c}157 \\
(\mathbf{5 2 . 3 3})\end{array}$ \\
\hline $\begin{array}{l}\text { Climate } \\
\text { change }\end{array}$ & $\begin{array}{c}6 \\
(16.2)\end{array}$ & $\begin{array}{c}1 \\
(2.7)\end{array}$ & $\begin{array}{c}9 \\
(24.3)\end{array}$ & $\begin{array}{c}6 \\
(16.2)\end{array}$ & $\begin{array}{c}15 \\
(40.5)\end{array}$ & $\begin{array}{c}37 \\
(12.33)\end{array}$ \\
\hline \multicolumn{7}{|c|}{ 4.1.2 Loss of CPRs affect life (Directly/ Indirectly) } \\
\hline Yes & $\begin{array}{c}32 \\
(16.5) \\
\end{array}$ & $\begin{array}{c}39 \\
(20.1) \\
\end{array}$ & $\begin{array}{c}46 \\
(23.7) \\
\end{array}$ & $\begin{array}{c}37 \\
(19.1) \\
\end{array}$ & $\begin{array}{c}40 \\
(20.6)\end{array}$ & $\begin{array}{c}194 \\
(64.66)\end{array}$ \\
\hline No & $\begin{array}{c}28 \\
(26.4)\end{array}$ & $\begin{array}{c}21 \\
(19.8)\end{array}$ & $\begin{array}{c}14 \\
(13.2)\end{array}$ & $\begin{array}{c}23 \\
(21.7)\end{array}$ & $\begin{array}{c}20 \\
(18.9)\end{array}$ & $\begin{array}{c}106 \\
(35.33)\end{array}$ \\
\hline \multicolumn{7}{|c|}{ 4.1.3 Choosing livelihood alternative due to loss in CPR } \\
\hline Yes & 35 & 37 & 29 & 36 & 29 & 166 \\
\hline
\end{tabular}




\begin{tabular}{|c|c|c|c|c|c|c|}
\hline & $(21.1)$ & $(22.3)$ & $(17.5)$ & $(21.7)$ & $(17.5)$ & (55.33) \\
\hline don't know & $\begin{array}{c}25 \\
(18.7)\end{array}$ & $\begin{array}{c}23 \\
(17.2)\end{array}$ & $\begin{array}{c}31 \\
(23.1)\end{array}$ & $\begin{array}{c}24 \\
(17.9)\end{array}$ & $\begin{array}{c}31 \\
(23.1)\end{array}$ & $\begin{array}{c}134 \\
(44.66)\end{array}$ \\
\hline \multicolumn{7}{|c|}{ 4.1.4 Awareness about Importance of CPR by new generation } \\
\hline Yes & $\begin{array}{c}4 \\
(13.8)\end{array}$ & $\begin{array}{c}1 \\
(3.4)\end{array}$ & $\begin{array}{c}5 \\
(17.2)\end{array}$ & $\begin{array}{c}11 \\
(37.9)\end{array}$ & $\begin{array}{c}8 \\
(27.6)\end{array}$ & $\begin{array}{c}29 \\
(19.66)\end{array}$ \\
\hline May be & $\begin{array}{c}20 \\
(25)\end{array}$ & $\begin{array}{c}19 \\
(23.8)\end{array}$ & $\begin{array}{c}11 \\
(13.8)\end{array}$ & $\begin{array}{c}16 \\
(20)\end{array}$ & $\begin{array}{c}14 \\
(17.5)\end{array}$ & $\begin{array}{c}80 \\
(26.66)\end{array}$ \\
\hline Don't No & $\begin{array}{c}36 \\
(18.8)\end{array}$ & $\begin{array}{c}40 \\
(20.9)\end{array}$ & $\begin{array}{c}44 \\
(23)\end{array}$ & $\begin{array}{c}33 \\
(17.3)\end{array}$ & $\begin{array}{c}38 \\
(19.9)\end{array}$ & $\begin{array}{c}191 \\
(63.66)\end{array}$ \\
\hline \multicolumn{7}{|c|}{ 4.1.5 CPR loss affects life of new generation } \\
\hline Yes & $\begin{array}{c}38 \\
(22.5) \\
\end{array}$ & $\begin{array}{c}25 \\
(14.8) \\
\end{array}$ & $\begin{array}{c}31 \\
(18.3) \\
\end{array}$ & $\begin{array}{c}38 \\
(22.5) \\
\end{array}$ & $\begin{array}{c}37 \\
(21.9) \\
\end{array}$ & $\begin{array}{c}169 \\
(56.33) \\
\end{array}$ \\
\hline No & $\begin{array}{c}22 \\
(16.8)\end{array}$ & $\begin{array}{c}35 \\
(26.7)\end{array}$ & $\begin{array}{c}29 \\
(22.1)\end{array}$ & $\begin{array}{c}22 \\
(16.8)\end{array}$ & $\begin{array}{c}23 \\
(17.6)\end{array}$ & $\begin{array}{c}131 \\
(43.66)\end{array}$ \\
\hline \multicolumn{7}{|c|}{ 4.1.6 Willingness to continue living in the village } \\
\hline Yes & $\begin{array}{c}36 \\
(20.3)\end{array}$ & $\begin{array}{c}37 \\
(20.9)\end{array}$ & $\begin{array}{c}29 \\
(16.4)\end{array}$ & $\begin{array}{c}38 \\
(21.5)\end{array}$ & $\begin{array}{c}37 \\
(20.9)\end{array}$ & $\begin{array}{l}177 \\
(59)\end{array}$ \\
\hline No & $\begin{array}{c}24 \\
(19.5)\end{array}$ & $\begin{array}{c}23 \\
(18.7)\end{array}$ & $\begin{array}{c}31 \\
(25.2)\end{array}$ & $\begin{array}{c}22 \\
(17.9)\end{array}$ & $\begin{array}{c}23 \\
(18.7)\end{array}$ & $\begin{array}{l}123 \\
(41)\end{array}$ \\
\hline
\end{tabular}

Source: Computed from primary data; $\mathrm{N}=300$

\subsubsection{Possible effects of loss of CPR}

As well as overcrowding, another important cause of degradation is a slackening of traditional management. State interventions have been ineffective in substituting formal for the previous informal social sanctions and customary arrangements for protecting, upgrading and regulating the use of common property. As a result, many have become open access resources, with everyone using them without any reciprocal obligation to maintain them. Above table shows that, at present, nearly $90 \%$ of villages fail to enforce historical regulations, both formal and informal. Survey reveals that nearly 52 percentage of respondents recorded that loss of CPRs affects their overall livelihoods, 34 percentage have recorded that loss of CPRs resulted in loss of local and traditional employment. The reduction in land area, poor maintenance and the decline in carrying capacity lead to reduced supplies of products for those who depend on common property resources. Seen in relation to earlier evidence of the rural poor's heavy dependence on these resources, their decline represents a definite positive step towards further pauperization of the poor. This is a classic case of the vicious circle of poverty and resource degradation reinforcing each other.

\subsubsection{Consequences of Loss of CPRs (Directly/ Indirectly)}

CPRs have historically been part and parcel of India's rural economy, culture, and tradition. They play a very crucial role in the survival of the most vulnerable sections of the rural poor, who have a very peripheral position in relation to the mainstream economy, and meager access to remunerative income-earning opportunities. CPRs provides with an array of 
consumer goods including, food, fiber, fodder, fuel, building materials, artisan' raw materials, small timber, medicinal herbs, resin, gum, honey and species for subsistence use and sale. They also provide many services of value to the people, namely space for off-season cropping, grazing, garbage disposal, animal keeping, public functions, and crop threshing. CPRs further help to alleviate the problem of poverty by providing income-earning opportunities, especially to poor households, to reduce unemployment through generating employment and to improve the ecological system through their sustainable use and management. The above table clearly indicates the views of sample households on the loss of CPRs and its effects on their livelihood in the study areas. It is noted from the above that majority of sample households $(64.66 \%)$ have reported that the loss of CPRs had its effect on their livelihoods directly and indirectly. However, 35.33\% of them didn't experience the ill effect of loss of CPRs in their livelihoods. A number of welfare and development interventions have had severe negative side effects on CPRs. CPR land has been lost severely. Such declines in CPRs have also been noted that the poor households are losing access to CPRs.

The nature of the effect of loss of CPR as reported by the sample households is presented in the above table. It is noted from the table that effects such as climate change $(21.66 \%)$, pollution $(24 \%)$ and water scarcity $(12.66 \%)$. Further, it was of the opinion of $26.66 \%$ of sample Households that loss of CPR in the study areas has altered their lifestyle artificially and other $15 \%$ of them reported that lack of Knowledge of management of CPRs and it is conservation were the reasons for loss of CPR and its consequences as reported above. It is noted from the table that the sample households don't feel the negative effective of CPRs decline as they depend more on provisions under government scheme (24\%), an increasing number of industries and creation of jobs (22\%). However, the sample households were of the opinion that they have experienced negative effects such as climate change, pollution artificial lifestyle on account of decline CPRs. Further, it is noted from the table that the local community had little control over CPR governance and people were lacking knowledge of the management and conservation of CPRs. These reasons have also contributed for the decline of CPRs in the study areas.

\subsubsection{Choosing livelihoods alternative due to loss of CPRs}

Decentralized collective management of CPRs by their users could be an appropriate system for overrating the 'tragedy of commons'. More careful analysis of the foundation of CPRs regimes in developing countries has shown that local institutional arrangements including customs and social conventions designed to induce cooperative solutions can overcome the collective action problem and help achieve efficiency in the use of such resources. Effective implementation of activities to ensure the equity and optimal welfare of poor people whose livelihoods are directly dependent on the long-term management of natural resources. The views on the need for exploring alternative livelihood opportunities due to loss CPRs as stated by sample households are presented in above table, It is noted that $55.33 \%$ of them felt the need for exploring the alternative livelihood opportunities as they have experience loss of CPRs. In the case of $44.66 \%$ of sample, households have expressed 
that they were not in need of alternative livelihood opportunities as they were able to manage the situations by themselves.

\subsection{Knowledge of the importance of CPRs by next generation}

There is a growing awareness of the significance of Common Property Resources (CPRs) in the rural areas. In the past, these resources were neglected by policy makers and planners. The increasing population pressure, institutional changes, privatization, commercialization, mechanization have played an important role in the deterioration of these resources. The views of sample respondents on their realization on the importance of CPRs by the upcoming generations and their family are present table. It is noted from the above table that the majority of the sample respondents (19.66\%) stated that they did not know whether the upcoming generations has realized the importance of CPRs or not. And $12.1 \%$ of them stated that their children have realized the need for CPRs. In the case of $31.3 \%$ of them were thoughtful of whether the upcoming generations realized the importance of CPRs in rural families and their economy. Common Property Resources (CPRs) are one of the most important resources known to man since times immemorial. The primitive man started his life from CPRs and depended on them for meeting his needs of fuel, fodder, food, medicines, shelter, and clothing. Even today, man has to depend on CPRs for his basic requirements. Besides, the physical supply of different products, these resources generates employment and income to the rural population. In addition, these resources also maintain the ecological balance of the region.

\subsubsection{CPR loss affects life of new generation}

The possible effect of Loss of CPR on the next generation and as expressed by sample respondents is depicted in above table. It is observed from the table that $56.33 \%$ of them were of the opinion that the loss of CPRs will have a possible effect on the next generations and such effect appears to be imminent. And whereas it was of the opinion of $43.66 \%$ of sample households that it will not have much effect on the next generations even due to loss of CPRs the study areas. Further, it is revealed by the sample respondents that establishment of more industries for providing employment opportunities and creating provisions under the government schemes would help the upcoming generations to cope-up with the possible decline of CPRs in the future.

\subsubsection{Willingness to continue living in villages}

Developing countries depend on a number of important ways in their natural capital. Peasants, fishermen and cattle herders earn their living directly from the utilization of renewable natural resources such as farm land, water, air, forest, grazing areas, irrigation, plants, and animals. In many countries, these resources are increasingly exposed to unsustainable exploitation, pollution, and conversion to other uses. When natural resources degrade or perish, peoples' livelihoods disappear, aggravating problems of rural poverty, food insecurity, and rural-urban migration. The above table presents the opinion of sample households on their continuation in the present villages even under the decline the CPRs capital. Even with the fact that CPR capital has been steadily declining, 5\% sample 
households wanted to continue to live in the same villages where they are presently living and whereas $41 \%$ of them do not want to continue their stay in the same village.

\section{SUMMARY OF FINDINGS}

* The immediate consequence of loss of CPRs on such resources is their overexploitation and degradation. Their physical degradation is strongly felt and observed, but its quantification is difficult owing to a lack of benchmark data. Nevertheless, case histories and close monitoring do provide basic details. Declines in the number of products available and their yields are the main indicators of physical depletion.

* This study also dwelt on the knowledge of sample respondents on the traditional ways of management of CPRs namely, Land, Water, and forest resources. Very interestingly it is learned that the sample respondents were aware of traditional systems of management. The householders were aware of provision made available under the programmes implemented by governments for preserving the CPRs.

Among the surveyed blocks with $21 \%$, respondents of Dindigul and Sanarapatti were highly aware of the topic and respondents from Oddanchatram and Vadamadurai with $33.3 \& 22.9 \%$ respectively have low awareness about the topic Increase of Population which is directly associated with the decline of CPRs as resources are limited. In which the highest number of respondents were from Reddiyarchatram with $30 \%$ among the surveyed blocks. The overall increase in or having high Pressure on CPRs occur due to various factors such as population, lack of other dependable resources, mismanagements.

* Among the surveyed blocks with 20.7 \& 20.3\% respondents from Dindigul \& Sanarapatti respectively have reported that there is a lack of traditional practices of management among the present communities.

* With 25\% respondents from Reddiyarchatram \&Vadamadurai have reported that there is no lack of traditional practices of management, according to them still, the management practices are going on as per traditional practices.

* However, $92 \%$ of respondents from the study are lacking knowledge of traditional practices of management.

* Lack of conservation activities is could be directly associated with unawareness about the importance of CPRs which further could be associated with another factor such as either people are fewer dependents or have no control over CPRs. Dependency on CPRs for Housing material is a very primary activity for the dependent communities and also it is an age-old practice.

\section{Conclusion}

Common Property Resources are widely used by all the people of the village, it is regulated by government institutions and by the local communities. Each and everyone in the village have exclusive rights to access commons despite some discrimination based on caste and community. Given then the dual existence of high levels of poverty and dependence on local common resources, the question arises as to whether improved natural resources management can form the basis of poverty alleviation policies in rural India. Earlier studies have found that resource dependence strongly decreases with income. However, this study 
finds that there existed more complex relationship--contrary to the common wisdom that rich households are just as dependent on natural resources as the poor, though the rich and the poor depend on different resources. There are various schemes and program introduced by the government but despite their strategies to reduce poverty, it remains a major challenge. Study of various researches reveals that there is a need for multi-prolonged strategies to tackle the multi-dimensional nature of poverty. From the present study, it is established that common property resources provide livelihoods to rural dependent communities. Hence, conservation and proper management of CPRs could be the prime priority of micro-level planning.

\section{BIBLIOGRAPHY}

Pathania M.S, et.al (2019), "Common Property Resources and the Environmental Context: Role of Bio-physical versus Social Stresses", Economic and Political Weekly, Vol.No.30 (51), 23.pp.3278-3283.

Beck, Tony. Madan G Ghosh (2017), "degradation of Common Property Resources and the Poor: Findings from West Bengal”, Economic and Political Weekly. 35:3: 147-153.

Curtis R. Martins (2017) AMADI-Midlands State University 1st floor Embassy House, Gwamile Street/Msakato Street P. O. Box 6146 Mbabane Kingdom of Swaziland. Email: curtismartinsr@gmail.com.Accepted 3 July, 2013

Murugesan .P and D. Namasivayam (2016), "Common Property Resources and the dimensions of Rural Poverty in Tamil Nadu”, Journal of Humanities, Vol-II

Mengistu Dessalegn (2016) Threatened common property resource system and factors for resilience: lessons drawn from serege-commons in Muhur, Ethiopia, Ecology and Society 21(4):22. http://dx.doi.org/10.5751/ES-08768-210422

Chopra and Gulati (2013). "Migration, Common Property Resources and Environmental Degradation: Interlinkages in India's Arid and Semi-arid Regions." Sage Publications India Pvt. Limited: New Delhi.

Ostrom, Elinor. (1990). Governing The Commons: The Evolution Of Institutions For Collective Action. 10.2307/3146384.

Atrayee Banerjee and Chowdhury Madhurima (2013) Forest degradation and livelihood of local ommunities in India: A human rights approach Human Rights, Department of Anthropology, University of Calcutta, India.

Davidar, P., et. al. (2010). Assessing the extent and causes of forest degradation in India: Where do we stand? Biological Conservation 143: 2937-2944.

Debnarayan Sarker(2009). Sustainable Rural Livelihoods under Joint Forest Managment (JFM) Programme: An Evidence from West Bengal, India, Artha Vijnana, Gokhale Institute of Politics and Economics, Poona, Vol LI, No .1, March 2009,pp.59-84.

Elizabeth Et.al(April 2009) Discussion paper, Changing Access to Forest Resources in Tanzania, Elizabeth J.Z. Robinson and George C. Kajembe, Department of Economics, University of Dar-es-Salaam, Tanzania

Dasgupta Partha (2005), "Common Property Resources: Economic Analytics", Revised, March University of Cambridge. 
Boyce, James K., and Manuel Pastor (2001) Building Natural Assets: New Strategies for Poverty Reduction and Environmental Protection. Amherst, MA: Political Economy Research Institute.

Bon Emmanuel (2000), "Common Property Resource: Two case studies", Economic and Political Weekly vol.34, No.29, July 15, PP2569-2573 